\title{
Factors driving Arabian gazelles (Gazella arabica) in Israel to extinction: time series analysis of population size and juvenile survival in an unexploited population
}

\author{
Benny Shalmon ${ }^{1,2} \cdot$ Ping Sun $^{3} \cdot$ Torsten Wronski $^{4}$
}

Received: 2 January 2019 / Revised: 11 October 2019 / Accepted: 14 October 2019 /

Published online: 21 October 2019

(C) The Author(s) 2019

\begin{abstract}
Wild populations of Arabian gazelles (Gazella arabica) were once common on the Arabian Peninsula, but today disappeared from large parts of their former range. In Israel only a small population of currently 30 individuals survived, although it was - and still is - well protected from illegal hunting and habitat destruction. In our study we aimed to identify the factors influencing the population growth of G. arabica in Israel over the last two decades (1995-2017). We tested the impact of five environmental variables including annual mean maximum temperature, rainfall, the availability of two major food plants, competition with sympatric dorcas gazelle (G. dorcas) and predation (mainly by wolves) on two dependent variables relating to population viability (population size, percentage fawn survival) using a retrospective time series analysis. After testing for autocorrelations, two generalized least squares (GLS) models with autocorrelations at 3 and 6 years [GLS-AR(3,6)] were identified as the best models to explain environmental effects on populations size. Wolf encounter rate had a significant negative effect on $G$. arabica population size, while G. dorcas population size had a significant positive effect, suggesting that wolf predation shapes the population size of both gazelle species. For percentage fawn survival, model residuals did not reveal any significant autocorrelation and the best fit GLS-AR(0) model retained only wolf encounter rate and mean annual maximal temperature as significant predictors. This result suggests a strong impact of wolf predation and increasing temperatures on the fawn survival of Arabian gazelles. Changed rainfall patterns, food availability and competition between gazelle species had no impact on fawn survival.
\end{abstract}

Keywords Gazella arabica acaciae · Predation · Competition · Food availability · Climate $\cdot$ Israel

Communicated by David L Hawksworth.

Electronic supplementary material The online version of this article (https://doi.org/10.1007/s1053 1-019-01884-8) contains supplementary material, which is available to authorized users.

Torsten Wronski

t_wronski@gmx.de

Extended author information available on the last page of the article 


\section{Introduction}

Wild populations of desert ungulates have faced dramatic declines in past decades (Durant et al. 2014; Newby et al. 2016; Stabach et al. 2017). Overhunting, but also habitat loss, desertification and climate change have contributed to this catastrophic loss (Newby et al. 2016). The Arabian oryx (Oryx leucoryx), for example, was eradicated in 1972 due to overhunting (Henderson 1974), but prior to extirpation in the wild, several captive breeding programmes were established to save the species from extinction (Talbot 1960; Stanley Price 1989). Similarly, the scimitar-horned oryx (Oryx dammah) is considered extinct in the wild (IUCN/SSC Antelope Specialist Group 2016), but survived in a number of captive breeding populations and more recently at two reintroduction sites in Tunisia and Chad (Gordon and Gill 1993; Newby 2016). Other desert ungulates were less fortunate: of the 15 large ungulate taxa found across the Saharo-Arabian region, three are now extinct, including the Saudi gazelle (Gazella saudiya), the northern bubal (Alcelaphus buselaphus buselaphus; IUCN/SSC Antelope Specialist Group 2009) and the Syrian wild ass (Equus hemionus hemippus; Groves 1986). Today, about $90 \%$ of arid-adapted antelope species are threatened with extinction (IUCN/SSC Antelope Specialist Group 2009).

Likewise, the conservation status of the Arabian gazelle (Gazella arabica) is alarming: once distributed from the Arava Valley in southern Israel along the mountains of western Saudi Arabia and Yemen into Oman and the United Arab Emirates, the species disappeared from large parts of its former distribution range (Magin and Greth 1994; Thouless et al. 1997; Mallon and Kingswood 2001). At present, a few isolated, natural or reintroduced populations persist (Thouless et al. 1997; IUCN/SSC Antelope Specialist Group 2017), with population sizes of often less than 100 individuals (Magin and Greth 1994; Thouless et al. 1997; Strauss et al. 2009; Boug et al. 2012; Wronski 2013; Wronski and Butynski 2014). Currently, the world population of G. arabica is estimated to be less than 12,000 individuals, prompting a IUCN red list classification as 'vulnerable' (IUCN/SSC Antelope Specialist Group 2017). In Israel's Arava Valley the population declined from several hundred in 1948 to 68 animals in 1968, the highest tally since counts were implemented (Shalmon 1991, 1997; Blank 1996, 2005). Currently, the population size is only 30 individuals (this study). Since 2006 the Arava population of G. arabica has been protected within a fenced enclosure in the Yotvata Nature Reserve (Cohen et al. 2013).

Despite tremendous management efforts to reverse the decreasing population trend of G. arabica in the Yotvata NR and numerous research projects to improve conservation of the species (Blank 1996, 2000, 2001, 2005; Hadas et al. 2015), there is still an ongoing debate on what factors shape the population growth of Arabian gazelles in Israel. Israel is the only country within the species distribution range, in which illegal hunting is not the main reason for its decline. Although illegal hunting has led to the current population size in Israel, the causes for the species decline in recent decades are rather natural than manmade and therefore represent an ideal study site to explore the vital causes for the species debility.

Essentially, five environmental variables, i.e., climate (rainfall, temperature), food availability, competition with sympatric dorcas gazelles ( $G$. dorcas), and most important, predation were discussed to have an impact on the population viability, here expressed as population size and percentage fawn survival. The Arava population occurs in an hyperarid depression at the most northern limit of the species' original distribution and is thus expected to be more vulnerable to climate changes (i.e., increasing temperatures, decreased precipitation; Yom-Tov and Ilani 1987; Dolev and Perevolotsky 2004; Polack, T., pers. 
com.), than populations dwelling in the higher, more humid altitudes of the Arabian Peninsula (Habibi 1991). It was therefore predicted that high annual mean maximum temperatures and low precipitation negatively influence the population growth of G. arabica in the Arava Valley. It was also proposed that a high availability of two major food plant species positively affects the population growth of Arabian gazelles (Breslau et al. 2019), since both tree species are essential for the survival of the species, not only in Israel but across the species distribution range (Vesey-Fitzgerald 1952, Wronski and Schulz-Kornas 2015, Wronski et al. 2017a, b). Competition for limited food resources with dorcas gazelles was also predicted to be a cause for the decline of G. arabica in southern Israel (Shalmon 1991, Breslau et al. 2019). Shalmon (1989) suggested that both species largely overlap in their dietary requirements, exploiting more or less the same two major food plant species. We thus used the G. dorcas population size in the study area as a proxy for inter-specific competition. Predation, mainly by wolves, is considered to be another variable with negative impact on the G. arabica population in the Yotvata NR. Populations of canine predators in Israel have increased in recent decades, mainly due to foraging on human discard, unharvested or dropped agricultural products and undisposed carcasses of domestic livestock (Shalmon 1986; Reichmann and Saltz 2005; Margolis et al. 2008; Cohen et al. 2013; Gingold et al. 2009; Talmon 2015; Barocas et al. 2018), leading to increased predation on their natural prey species. In our study, we aimed to ultimately identify the factors that influence the population viability of G. arabica in Israel over the last two decades (1995-2017) by assessing the above mentioned environmental variables.

\section{Methods}

\section{Study area}

The Yotvata NR is an alluvial fan area located at the edge of the Yotvata salt marsh in the southern Arava Valley at an altitude of $75 \mathrm{~m}$ above sea level (Evenari et al. 1971; Fig. 1). Within the Yotvata NR $\left(32 \mathrm{~km}^{2}\right)$, a fenced enclosure $\left(3.5 \mathrm{~km}^{2}\right)$ was established in July 2006, to protect the G. arabica population from wolf predation (Cohen et al. 2013). To date this fenced area of natural habitat represents the last stronghold of $G$. arabica outside the Arabian Peninsula. Depending on soil salinity, the Yotvata NR comprises six vegetation belts (Baharav 1980), of which only the Vachellia (formerly Acacia)-Anabasis community occurs within the G. arabica enclosure. The community is dominated by Vachellia raddiana and V. tortilis, accompanied by the semi-parasite Plicosepalus acaciae, and a number of shrubs such as Hammada salicornica, Anabasis articulata, Ochradenus baccatus, and Lycium shawii (Baharav 1980). Annual herbs and grasses are scarce or even absent in this community (Baharav 1980). The climate is hyper-arid with an annual mean temperature of $23.5^{\circ} \mathrm{C}\left(\max .: 38.7^{\circ} \mathrm{C}\right.$, min.: $8.8^{\circ} \mathrm{C}$; En.climate-data.org 2017), and unpredictable rainfall (averaging $35 \mathrm{~mm}$ per year) that occurs only between October and May (IMS 2018). Heavy, short rains cause flash floods that cross the G. arabica enclosure from west to east, draining into the basin of the Yotvata salt marsh. In October and November 2012, as well as in February 2013, these flash floods destroyed the fence allowing wolves (Canis lupus) - the main natural predator of G. arabica - to enter the enclosure. In June 2013, the fence was repaired and access for wolves prevented again (Shalmon pers. obs.). The $G$. arabica population shares the habitat and the enclosure with 40 to 170 dorcas gazelles $(G$. 


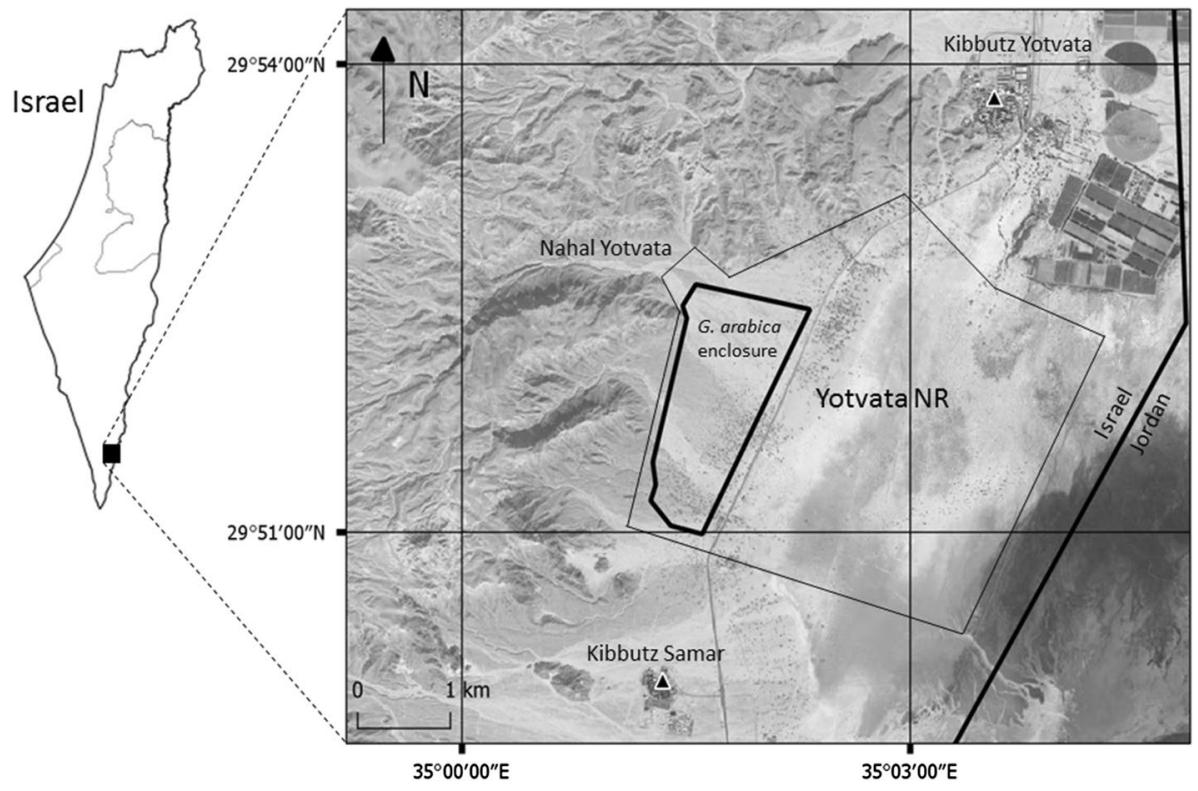

Fig. 1 Location of the Yotvata Nature Reserve in southern Israel and the position of the study area (G. arabica enclosure) within the Nature Reserve

dorcas), a species that directly competes with G. arabica for two major food plant species, i.e., Vachellia raddiana and V. tortilis (Breslau et al. 2019).

\section{Study species and population change}

Until recently, G. arabica was merged with the mountain or Palestine gazelle (G. gazella; Groves 1985, 1997; Mendelssohn et al. 1995), but split into at least seven subspecies (Groves and Grubb 2011), one of them being Gazella 'gazella' acaciae described from the southern Arava Valley in Israel (Mendelssohn et al. 1997; Fig. 2a). Recent phylogenetic and morphological investigations, however, favoured the division of this species complex into two species: G. arabica and G. gazella (Wronski et al. 2010; Bärmann et al. 2013a, b; Lerp et al. 2013; Hadas et al. 2015).

Until 1956 the G. arabica population in Israel numbered probably several hundred individuals in the Vachellia groves of the northern (Hazeva) and southern Arava Valley (Yotvata-Eilat). The northern population was eradicated between 1956 and 1963 due to illegal hunting by soldiers of the Israeli Defence Forces (Mendelssohn 1974). After 1964, only the southern population survived, being annually assessed by the Israel Nature and Parks Authority (INPA; Yom-Tov and Ilani 1987). This small population experienced pronounced variation in population size, with maximum numbers never exceeding 68 individuals and a minimum population size of only 10 animals in 1996 and 11 in 2005 (this study). From 1964 to 1983 the populations' range was reduced to the Arava Valley between Eilat in the south and Yotvata in the north. Since 1983 the population is restricted to its preferred habitat, i.e., the Vachellia groves of the Yotvata NR. The current population size (in 2019) is 30 individuals, with 10 males, 13 females and 7 juveniles (Shalmon pers. obs.). 

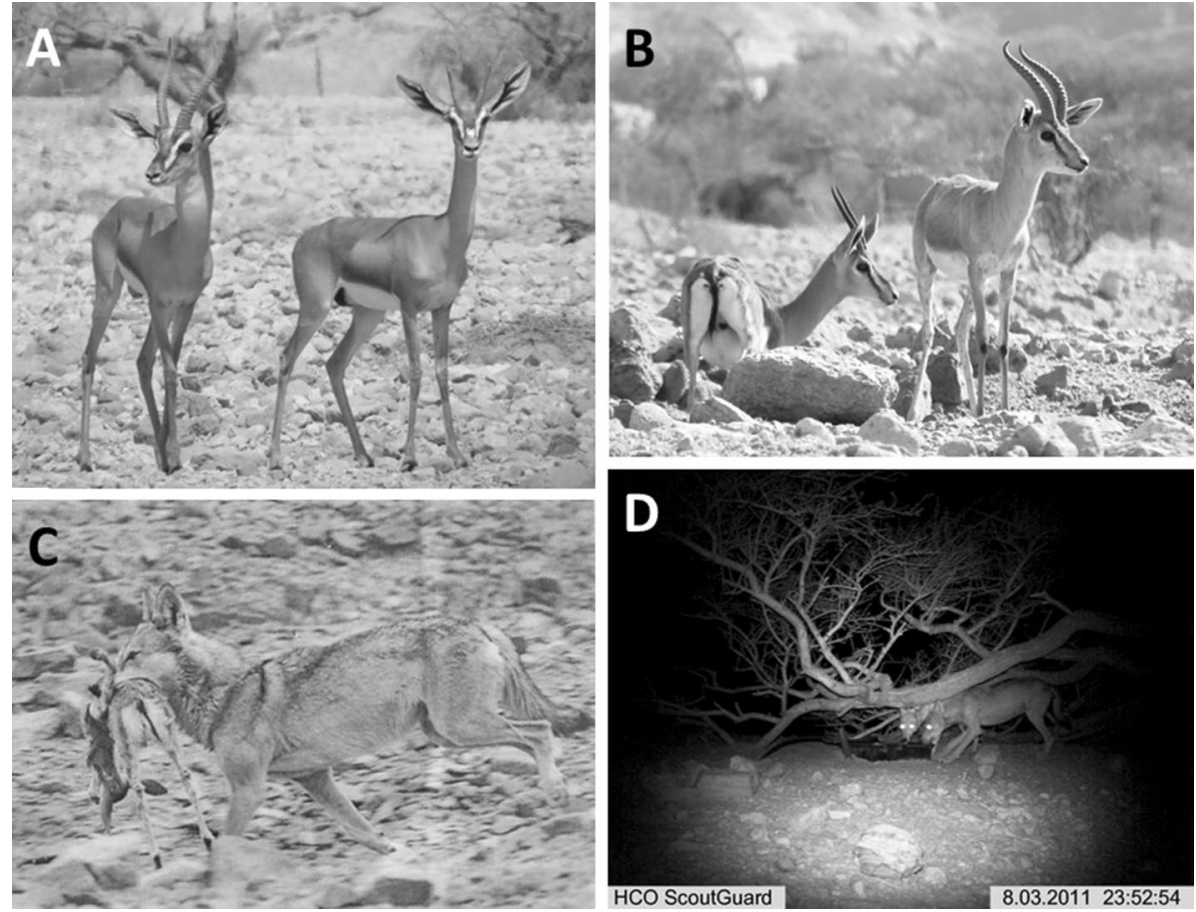

Fig. 2 a Male and female G. arabica in the Yotvata NR, b male and female G. dorcas in the Yotvata NR, c wolf carrying a dead gazelle fawn at Timna Desert Park, app. $8 \mathrm{~km}$ south of the study area, d camera trapping image showing two adult wolves at an artificial water source in the Yotvata NR after climbing the fence in March 2011

\section{Annual counts of G. arabica and G. dorcas}

From 1995 to 2005, annual counts of Arabian and dorcas gazelles (Fig. 3a, b) were carried out by the INPA as described in Yom-Tov and Ilani (1987). After fencing in 2006, total drive counts (sensu Bothma 2002) were conducted within the G. arabica enclosure during autumn (October to November). Three to five vehicles, each with a driver and one observer, were slowly $(5 \mathrm{~km} / \mathrm{h})$ driven from south to north, driving gazelles towards the northern fence. Those gazelles trying to escape across the drive line between the vehicles were counted by one of the observers. Eye and radio contact between observers prevented double counting. Since 2010, two such counts were conducted; one in summer (June-July), another one in winter (December-February), and results were averaged across each year (Fig. 3). In 2017 the number of counts was increased to four, i.e., two in each season. Moreover, due to long-term observations by INPA staff most adult females were individually known (see below), contributing to the correct estimation of population size. Based on known female-male and female-juvenile ratios (Yom-Tov and Ilani 1987; Shalmon 1991), the missing count result of 1986 was estimated as 35. After 2006, dorcas gazelles outside the enclosure were not considered. 


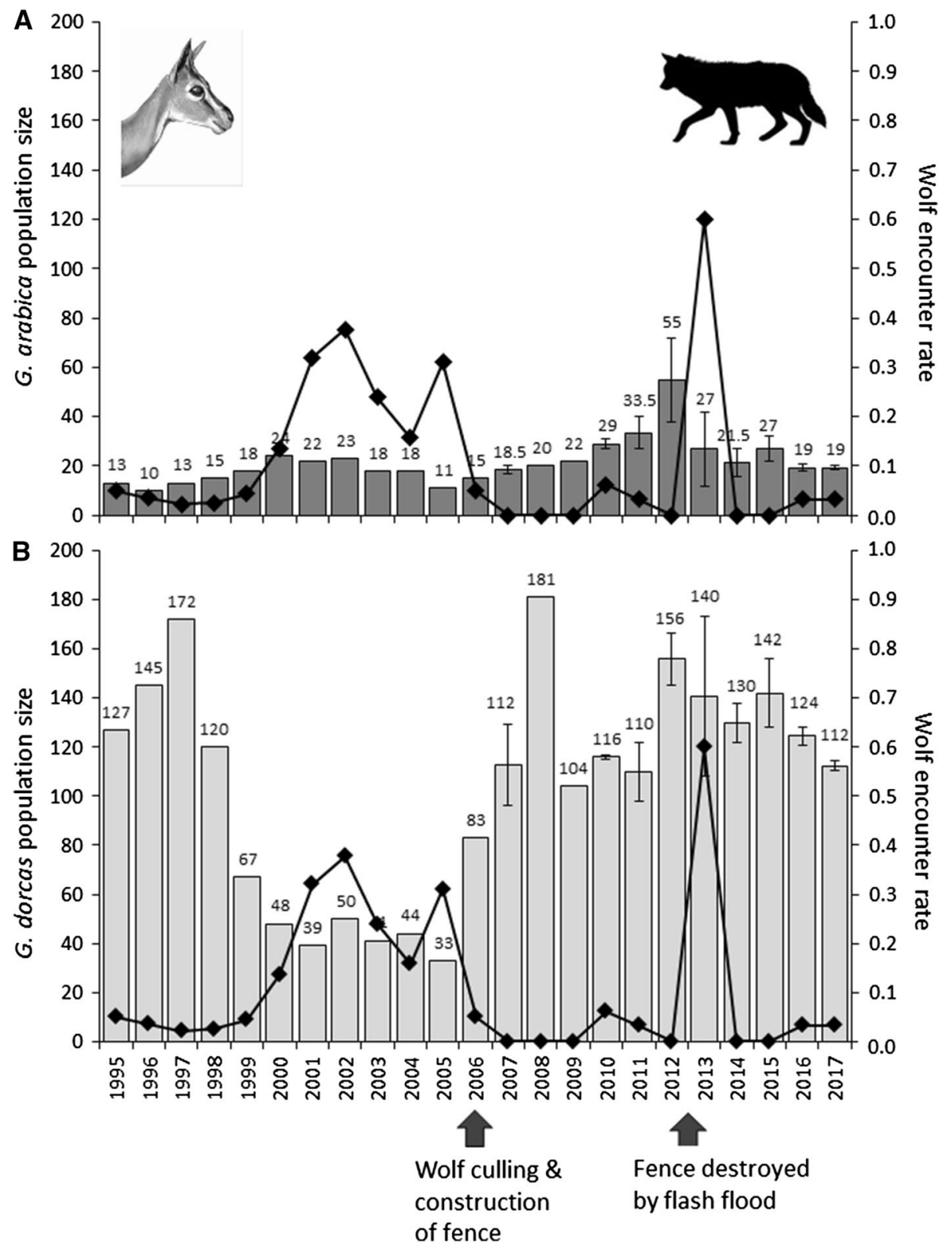

Fig. 3 Mean annual population size $( \pm \mathrm{SE})$ of Gazella arabica (a) and G. dorcas (b) in relation to wolf encounter rates as established in the Yotvata Nature Reserve from 1995 to 2017

\section{Fawn survival}

Percent fawn survival was calculated as the number of new-borns that survived for more than 5 months (i.e., the time when young males leave the maternal herd; Mendelssohn et al. 1995), as a proportion of all fawns born in the respective year. Month of birth and 
death were obtained during regular (daily) patrols in and around the enclosure carried out by INPA staff from 1995 to 2017 . Fawns were identified through their mothers, who were individually known based on their characteristic face markings and horn shapes (Fig. 2a).

\section{Climate (rainfall and temperature)}

Rainfall recordings were obtained from IMS (2018), taken at Yotvata settlement, $1.5 \mathrm{~km}$ north of Yotvata NR, while annual mean maximum temperature data were obtained from IMS (2018) for Eilat, the nearest weather station to the study area that recorded temperature for the relevant years. The annual mean maximum temperature was calculated as the average of monthly (January-December) maximum temperatures for each year.

\section{Food availability (Vachellia greenness)}

From 2000 to 2009 the food availability of two major food plants was measured as Vachellia tortilis and $V$. raddiana foliage greenness. Based on reference photos previously taken of both species in five different foliage stages, the greenness index was established by eyesight, using a green scale reaching from zero (no foliage) to five (maximum foliage). To determine greenness, photographs of both species were taken once a year in autumn at the beginning of the rainy season, using the same camera, location, distance, angle and camera settings. Average greenness was established for 30 trees of each species and then summed to obtain an overall greenness index for both species in each year. Missing values, from 1995 to 1999, were interpolated from adjacent values, i.e., the average from 2000 to 2008, that period in which data were obtained by visual estimation. After 2009, greenness was measured using near infra-red photographs to calculate the Normalized Difference Vegetation Index (NDVI).

\section{Competition (G. dorcas population size)}

Both, G. arabica and G. dorcas (Fig. 2a, b) feed mainly on the leaves, flowers and fruits of Vachellia trees (Shalmon 1991), suggesting a pronounced interspecific competition for food. Competition with $G$. dorcas was simply expressed as the number of dorcas gazelles present in the study area. From 1995 to 2017 both species were counted as described above (Yom-Tov and Ilani 1987).

\section{Predation (wolf encounter rate)}

In the Yotvata NR, wolves represent the only predator of both gazelle species (Shalmon 1991). Leopards (Panthera pardus nimr) are locally extinct, and caracals (Caracal cara$c a l$ ), golden jackals (Canis aureus) and striped hyenas (Hyaena hyaena) occur only sporadically in the study area. Red foxes (Vulpes vulpes) may scavenge on gazelle carcasses and afterbirths, but are too small to actively prey on gazelles (Mendelssohn 1974; Shalmon pers. obs.). From 1995 to 2005 a wolf encounter rate was established as a proxy of predation pressure in the respective year. Hereby, the number of wolves encountered (3-65 encounters/year) during INPA patrols was divided by the number of observer days in the study area (41-271 days/year). After fencing the G. arabica habitat in 2006, wolves were still able to enter the enclosure-although at a much lower frequency (Shalmon pers. 
obs.) - and to prey on the fawns and adults of both gazelle species (Fig. 2c). From 2006 to 2017 the annual wolf encounter rate was calculated as the number of wolves photographed by two camera traps permanently (365 days/year) located at two artificial water sources within the enclosure divided by the number of trapping days. To avoid overestimation of wolf encounter rates obtained from camera trapping, pictures taken on the same day were counted as only one encounter, unless two or more individuals were trapped on the same image (Fig. 2d). Individuals could not be distinguished by either survey method and wolf encounter rates may thus be biased by repeated sightings.

\section{Statistical analysis}

In all cases, measurements were averaged across samplings to obtain one value for each year (1995-2017). To achieve normal distribution, all absolute data, i.e., G. arabica population size, G. dorcas population size, greenness index, annual mean maximum temperature, rainfall and the wolf encounter rate were $\ln (\mathrm{x}+1)$ transformed. Relative data such as percentage fawn survival were arcsine (square root) transformed.

Initially, two generalized least squares (GLS) models ( $n l m e$ package in $R$; Pinheiro et al. 2012) without any autocorrelation process (AR), i.e., GLS-AR(0) models were conducted to explore the relationships between two dependent variables ( $G$. arabica population size and percentage fawn survival) and five environmental variables (i.e., G. dorcas population size, greenness index, annual mean maximum temperature, rainfall and wolf encounter rate). As our dataset contains longitudinal time series observations, we examined whether autocorrelated residuals occurred within initial GLS regressions by using Auto Correlation Function (ACF) and Partial Auto Correlation Function (PACF) of dependent time series.

In case autocorrelated errors were detected, coefficients were estimated for the firstorder Autoregressive model AR(1) in combination with Restricted Maximum Likelihood (REML) of variance components. Subsequently, we expanded the autocorrelation process to another 5 years' time lag effect (i.e., every 1 year) and calculated the GLS-AR(2-6) models, before finally comparing nested models using Akaike Information Criteria (AIC). All environmental variables, as well as their two-way interaction terms were included in the initial model but removed using a stepwise backwards elimination procedure, to identify the best fit model with the smallest AIC and lowest residual standard error (SE). Unstandardized beta $(B)$, t-test statistics $(t)$ and variance inflation factor (VIF) were established and applied as described in Pinheiro et al. (2012) and Pekár and Brabec (2016). Inspection of model residuals did not indicate violations of model assumptions, i.e., normal error distribution and homoscedasticity. All data analyses were carried out in RStudio (version 3.5.1).

\section{Results}

\section{Population size}

The initial GLS-AR(0) model revealed mean annual maximum temperature to have a significant positive effect on $G$. arabica population size $(B=10.57, t=2.65, p=0.02$; Table 1). The GLS-AR(0) model residuals varied distinctly through time suggesting a substantial autocorrelation (Supplementary Material Fig. S1a). The ACF autocorrelogram of GLS-AR(0) model residuals showed a sinusoidal pattern with a negative autocorrelation $(r=-0.42)$ at time lag 6 (Supplementary Material Fig. S1b). The PACF 
Table 1 Initial GLS-AR(0) models of G. arabica population size and percentage fawn survival (dependent variables) with five environmental variables (rainfall, annual mean maximum temperature, greenness index, wolf encounter rate, and $G$. dorcas population size)

\begin{tabular}{llrrrrr}
\hline Dependent variable & Explanatory variables & $\begin{array}{l}\text { Estimated } \\
\text { coefficient }\end{array}$ & SE & $t$ & $p$ & VIF \\
\hline \multirow{2}{*}{ G. arabica population size } & Rainfall & -0.12 & 0.08 & -1.58 & 0.13 & 1.22 \\
& Wolf encounter rate & 0.07 & 0.41 & 0.16 & 0.87 & 2.19 \\
& Greenness index & 0.40 & 1.00 & 0.40 & 0.70 & 1.47 \\
& Mean annual max. temp. & 10.57 & 3.99 & 2.65 & $\mathbf{0 . 0 2}$ & 1.46 \\
& G. dorcas population & 0.01 & 0.19 & 0.03 & 0.98 & 2.08 \\
Percentage fawn survival & Rainfall & 0.02 & 0.05 & 0.36 & 0.72 & 1.22 \\
& Wolf encounter rate & -0.66 & 0.29 & -2.31 & $\mathbf{0 . 0 3}$ & 2.19 \\
& Greenness index & 0.00 & 0.70 & 0.01 & 0.99 & 1.47 \\
& Mean annual max. temp. & 4.04 & 2.78 & 1.45 & 0.16 & 1.46 \\
& G. dorcas population & 0.04 & 0.13 & 0.30 & 0.76 & 2.08 \\
\hline
\end{tabular}

Significant results $(p<0.05)$ are shown in bold font type

$S E$ standard error, $t$ t-test statistic, $p$ level of marginal significance, VIF variance inflation factor

autocorrelogram of model residuals showed no significant autocorrelations $(|r|<0.4$; Supplementary Material Fig. S1c). Considering all potential autoregression processes from AR(1) to AR(6), GLS-AR(3) and GLS-AR(6) were identified as the best autocorrelation models (Supplementary Material Table S1). The GLS-AR(3) model revealed that the $G$. dorcas population size had a significant positive effect on the G. arabica population size $(B=0.40, t=2.80, p=0.01$, Supplementary Material Table S1). The GLS-AR(6) model further confirmed that the G. dorcas population size had a significant positive effect on the $G$. arabica population size $(B=0.48, t=6.86, p<0.001)$, while the wolf encounter rate showed a significant negative effect $(B=-0.33, t=-0.36, p=$ 0.003; Supplementary Material Table S1). After applying a stepwise backwards elimination procedure, only wolf encounter rate and $G$. dorcas population size were retained as predictors for the G. arabica population size in the final models (Table 2). Both final models revealed that the wolf encounter rate had a significant negative relationship with the $G$. arabica population size (GLS-AR(3): $B=-0.37, t=2.73, p=0.01$; GLS-AR(6): $B=-0.29, t=-2.75, p=0.01$; Table 2, Figs. 3a, 4), while $G$. dorcas population size

Table 2 Final best fit GLS-AR(3) and GLS-AR(6) models with the smallest AIC and smallest residual standard error (SE) for $G$. arabica population size (dependent variable); $B$ unstandardized beta, $t$ t-test statistic, $p$ level of marginal significance, VIF variance inflation factor

\begin{tabular}{lllrrrrr}
\hline Model & AIC & Explanatory variables & \multicolumn{1}{l}{$B$} & SE & \multicolumn{1}{l}{$t$} & $p$ & VIF \\
\hline GLS-AR(3) & \multirow{2}{*}{11.26} & Intercept & 1.31 & 0.65 & 2.01 & 0.06 & \\
& & Wolf encounter rate & -0.37 & 0.13 & -2.73 & 0.01 & 1.06 \\
& & G. dorcas population & 0.41 & 0.14 & 2.90 & 0.01 & 1.06 \\
GLS-AR(6) & \multirow{2}{*}{9.58} & Intercept & 1.19 & 0.32 & 3.68 & 0.00 & \\
& & Wolf encounter rate & -0.29 & 0.11 & -2.75 & 0.01 & 1.21 \\
& & G. dorcas population & 0.44 & 0.07 & 6.39 & 0.00 & 1.21 \\
\hline
\end{tabular}


Fig. 4 Relationship between $\ln (\mathrm{x}+1)$ transformed G. arabica population size (dependent variable) and $\ln (x+1)$ transformed wolf encounter rate

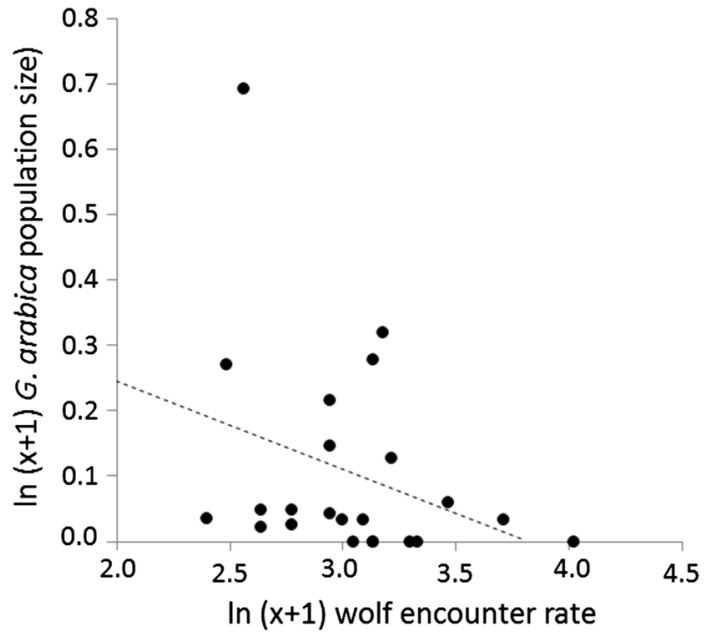

had a significant positive effect (GLS-AR(3): $B=0.41, t=2.80, p=0.01$; GLS-AR(6): $r=0.44, t=6.39, p<0.001$; Table 2, Fig. 3b).

\section{Percentage fawn survival}

The initial GLS-AR(0) model revealed wolf encounter rate to have a significant negative effect on percentage fawn survival $(B=-0.66, t=-2.31, p=0.03$, Table 1$)$. The GLS$\mathrm{AR}(0)$ model residuals showed a stochastic distribution, suggesting no autocorrelation (Supplementary Material Fig. S2a). Both, the ACF and PACF autocorrelogram of GLSAR(0) model residuals did not reveal any significant autocorrelation (Supplementary Material Fig. S2b, c). After applying a stepwise backwards elimination procedure, the best fit GLS-AR(0) model retained only wolf encounter rate and the mean annual maximal temperature as predictors (Table 3). Wolf encounter rate was found to have a significant negative correlation with the percentage fawn survival $(B=-0.7, t=-3.80, p<$ 0.01 ; Table 3, Fig. 5a), while mean annual maximal temperature was significantly positive related to percentage fawn survival ( $B=4.62, t=2.11, p=0.05$; Table 3, Fig. 5b).

Table 3 Final best fit GLS-AR(0) model for percentage fawn survival (dependent variable)

\begin{tabular}{lllllrlr}
\hline Model & AIC & Explanatory variables & $B$ & SE & $t$ & $p$ & VIF \\
\hline \multirow{2}{*}{ GLS-AR(0) } & \multirow{2}{*}{0.44} & Intercept & -15.2 & 7.63 & -1.99 & 0.06 & \\
& & Wolf encounter rate & -0.70 & 0.18 & -3.80 & 0.00 & 1.04 \\
& & Mean annual max. temp. & 4.62 & 2.18 & 2.11 & 0.05 & 1.04 \\
\hline
\end{tabular}



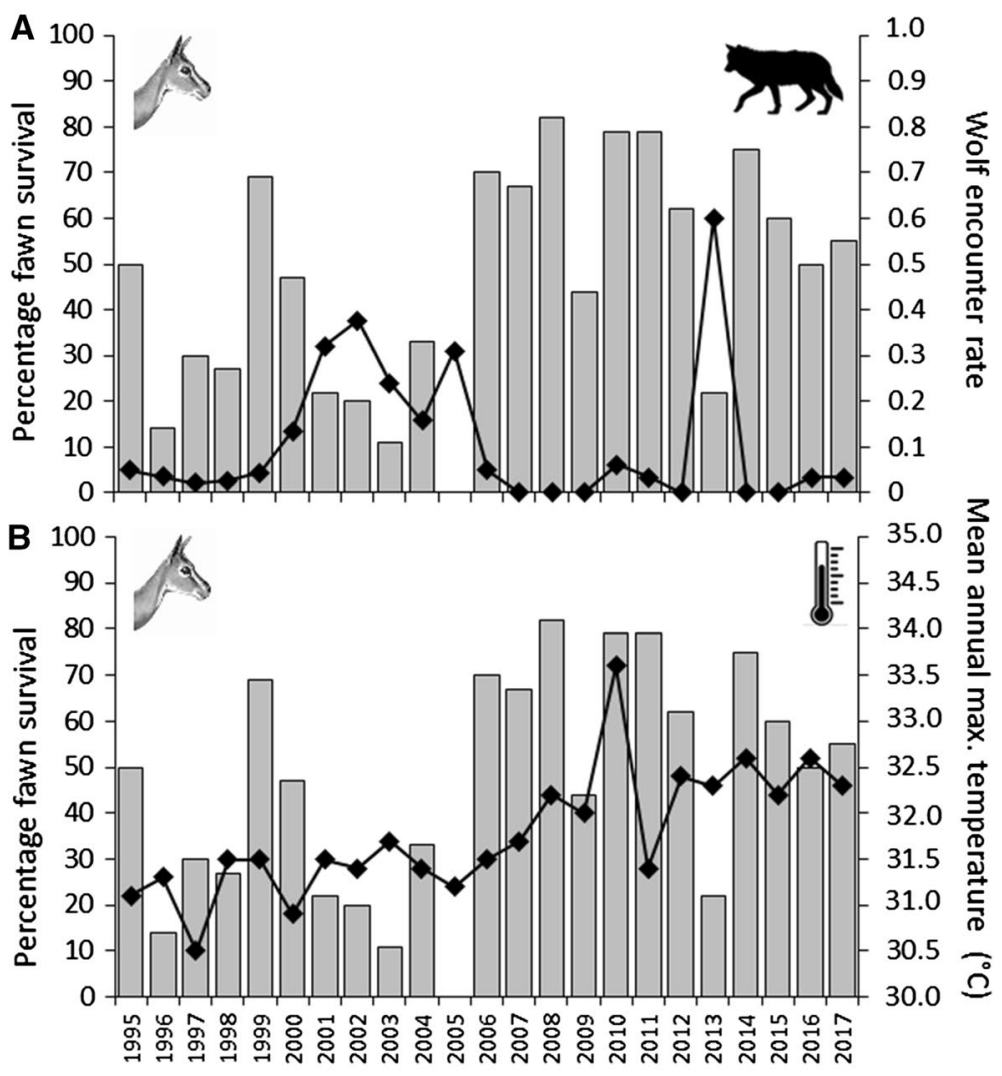

$\begin{array}{ll}\begin{array}{l}\text { Wolf culling \& } \\ \text { construction } \\ \text { of fence }\end{array} & \begin{array}{l}\text { Fence destroyed } \\ \text { by flash flood }\end{array} \\ \end{array}$

Fig. 5 Percentage fawn survival of the G. arabica population in the Yotvata NR from 1995 to 2017 in relation to wolf encounter rate (a) and mean annual maximum temperature (b). Markers indicate the construction of the fence in 2006 and its destruction by flash floods in 2012/13

\section{Discussion}

\section{Population size}

With our study we envisaged to define the factors shaping the population viability of Arabian gazelles in southern Israel, probably the only, currently unexploited — not huntedpopulation worldwide (Mallon and Kingswood 2001; IUCN/SSC Antelope Specialist Group 2017) and thus an ideal study population to identify reasons for their decline without having to consider the impact of poaching. However, at this point it should be also highlighted that a fenced population containing only 30 individuals is not ideal to examine natural processes. Five environmental variables were tested for their effects on two dependent variables representative for population viability (i.e., population size, percentage fawn 
survival). Our time series analysis (GLS models, Table 2) revealed two environmental variables influencing the $G$. arabica population size: (i) a negative effect of wolf encounter rate suggesting that predation by wolves has a strong impact on the population size of $G$. arabica and (ii) a positive effect of $G$. dorcas population size indicating an analogous population growth of both species, rather than competition. This is surprising since it was predicted that Arabian gazelles compete with sympatric dorcas gazelles for limited food resources (Shalmon 1989, 1991). Instead, it rather appears that the population growth of both species is subject to the same environmental stressors, i.e., predation by wolves (Fig. 3). Resource partitioning and reduced competition were reported from other ungulate communities such as swamp deer (Cervus duvauceli) and hog deer (Axis porcinus), two sympatric deer species from Nepal that consumed almost equal proportions of the same woody browse species (Wegge et al. 2006), or from the renowned grazing succession of migrant ungulates in the Serengeti Ecosystem (Sinclair and Norton-Griffiths 1982). Here, niche segregation has developed among grazing ungulates, allowing a relaxed co-existence but facing a similar predation pressure (Sinclair 1985; Putman 1996; Arsenault and OwenSmith 2002). Our result unrevealed not only a similar predation pressure on both gazelle species, but also two periodic population cycles, i.e., 3 and 6 years', reflected by the two time lag effects of GLS-AR(3) and GLS-AR(6) models. Such fluctuating population size patterns are known from other coupled predator-prey cycles (e.g. snowshoe hare, Lepus americanus and the Canadian lynx, Lynx canadensis; Elton and Nicholson 1942; Keith 1963; Krebs et al. 1995), suggesting bottom-up control of wolf populations by prey availability when gazelle population size (both species together) is high, and top-down control by wolves when wolf abundance is high. Likewise, predators consume more prey items per capita when prey densities are high and less when prey densities are low (Adamcik et al. 1978). In the present case, this predator-prey cycle could be 6 years, whereby the 6 years' time lag represents high gazelle densities and the 3 years' time lag high wolf densities or vice versa. Unless further time series analysis include longer sampling periods to confirm such a cycle, this remains speculative and possibly biased by management actions such as culling of wolves and fencing the prime habitat of the gazelles.

Finally, food availability, measured as Vachellia greenness, and rainfall had no significant effect on the G. arabica population size (Supplementary Material Table S1). This finding refutes the prediction that the Arava population occurs in sub-optimal habitat at the limit of the species' original distribution and is thus more vulnerable to climate change, i.e., increasing temperatures and decreased precipitation than other populations on the Arabian Peninsula (Yom-Tov and Ilani 1987; Dolev and Perevolotsky 2004; Polack, T., pers. com.).

\section{Fawn survival}

Percentage fawn survival of Arabian gazelles in the Yotvata NR was determined by a strong negative effect of wolf encounter rate (Table 3, Fig. 5a) and a weaker positive effect of mean annual maximum temperature (Table 3, Fig. 5b), suggesting that higher temperatures and lower wolf encounter rates benefit the survival of G. arabica fawns. This finding corresponds to our results on population size, providing another strong argument that wolf predation shapes the $G$. arabica population size in the study area, at least since it was protected by the fence in 2006. Apart from habitat destruction and fragmentation, predation by carnivores-mainly wolves, but also jackals and straying dogs-is considered the major reason for the decline of gazelle populations in Israel (Gingold et al. 2009; Yom-Tov 
2013). This applies likewise to the G. gazella populations in northern Israel and the Golan Heights (Reichmann and Saltz 2005; Gingold et al. 2009; Manor and Saltz 2004; Geffen et al. 1999; Shamoon et al. 2017), to the G. dorcas population in the Negev Desert and the Arava Valley (Shalmon 1986; Margolis et al. 2008; Barocas et al. 2018), but alsoas our study has shown - to the G. arabica population. Canine predators in Israel have noticeably increased in recent decades (Gingold et al. 2009; Borkowski et al. 2011; Talmon 2015), mainly due to foraging on human discard, unharvested or dropped agricultural products and undisposed carcasses of domestic livestock (Shalmon 1986; Reichmann and Saltz 2005; Margolis et al. 2008; Gingold et al. 2009; Talmon 2015; Barocas et al. 2018), leading to an increased predation on their natural prey species. By contrast, Cohen et al. (2013) reported that there is no direct evidence of wolf predation on dorcas and Arabian gazelles in the Negev Desert (only 6.3\% of scat samples contained gazelle components), and Barocas et al. (2018) demonstrated that gazelle occurrence in Israel is not a predictor for habitat selection and movement patterns of wolves.

At this point it should be highlighted that the wolf encounter rate, as established in our study, was based on two different survey methods, i.e., on sightings obtained during daily patrols and on camera trapping images recorded at two artificial water sources. Although sightings and trapping events were standardised by taking the observation time into consideration, our results might be biased by this discrepancy. Nevertheless, the statistical support of our models seems to be robust enough to preclude the possibility that this methodological shortcoming has biased our overall result. During the 2012/13 flash floods and the subsequent collapse of the fence (Figs. 3, 5), wolves entered the enclosure and killed about 40 Arabian and 50 dorcas gazelles within a few weeks (Shalmon pers. obs.). Such surplus killing (sensu Kruuk 1972) is well described for canine predators (Andelt et al. 1980; Miller et al. 1985; DelGiudice 1998) and has-without much doubt-strongly contributed to the significant predation effect in our model. There are two main reasons why our findings are not applicable to populations on the Arabian Peninsula: the decline of Arabian gazelles on the Arabian Peninsula is mainly attributed to illegal hunting (Thouless et al. 1997; IUCN/SSC Antelope Specialist Group 2017), and secondly, wolves suffer exactly the same threat, i.e., severe persecution (Cunningham et al. 2009; Cunningham and Wronski 2010). Only, if human persecution of prey and predator can be controlled, the findings of our study would become applicable.

Interestingly, fawn survival of Arabian gazelles in the Yotvata NR benefited from increasing annual maximum temperatures, rather than suffering from adverse climatic effects instigated by global warming (Williams et al. 2012). On the contrary, G. arabica fawns kept in captivity are known to be prone to infections (e.g. brucellosis) when weather conditions are cold, wet and windy (Soares et al. 2019). The steady increase of both, fawn survival and temperature, over time might be an artefact owned to an autocorrelation among the variables included into our model. However, possible autocorrelations were not detected within our GLS (Supplementary Material Fig. S2), and are thus unlikely to be the cause for this positive relationship. Moreover, the overall study period of 20 years may have been too short to detect a long-term pattern in our data. Given that G. arabica seems to be well adapted to the hot desert climate of the Uruq Bani Ma'arid Protected Area in southern Saudi Arabia, where Arabian gazelles were reintroduced into a hyper-arid environment and population size increased rapidly (Islam et al. 2011; Wronski et al. 2013), it is unlikely that fawn survival in the equally hot climate of the Arava Valley is negatively affected by these climatic variables. Moreover, the largest stronghold of G. arabica is the Farasan Islands population that is thriving relatively well in the hot, muggy climate of Red Sea islands (Wronski 2013). Again, the prediction that the Arava population occurs at the 
northern most limit of $G$. arabica's original distribution and may be thus more prone to climate change (i.e., increasing mean annual maximum temperature) than populations on the Arabian Peninsula (Yom-Tov and Ilani 1987; Dolev and Perevolotsky 2004; Polack, T., pers. com.), was therefore rejected.

\section{Management implications}

Two major threats to Arabian gazelles were identified by the IUCN Red list (IUCN/SSC Antelope Specialist Group 2017), i.e., illegal hunting for meat and live capture for pets, and competition with domestic livestock. Since goat and sheep grazing as well as illegal hunting were prevented since 1949 and 1960 respectively (Mallon and Kingswood 2001), none of these threats applies to the current G. arabica population in the Arava Valley. Instead, the effect of wolf predation appears to be the dominant factor shaping the population of both gazelle species. It is thus imperative for the survival of the G. arabica population to sustain anti-predator protection at a maximum, i.e., keeping the fence in place and ensuring its regular maintenance. Furthermore, the disposal of human discard, such as garbage and agricultural products need to be reduced (or banned), and if necessary wolves need to be culled at low rates after careful discussion with all stakeholders involved. Once, the $G$. arabica population size has reached a self-sustaining, stable level these measures should be reassessed and adjusted to the new situation. It is further recommended to investigate the population genetics of G. arabica in the Yotvata NR with regard to population viability, inbreeding and a male biased natal sex ratio. With reference to previous and recent suggestions (Mallon and Kingswood 2001; Polack, T., pers. com.), we also recommend to move a small portion of the G. arabica population to a captive breeding unit that is entirely protected from predation by wolves and that could facilitate juvenile survival leading to a rapid increase of overall population size. Young adult individuals should be then reintroduced to supplement the remaining 'wild' population. One important ecological aspect that was not considered in our study is the health status of Arabian and dorcas gazelles in the study area. It is thus recommended to look into this aspect and carry out a parasite screening with focus on gastro-intestinal parasites, protozoan infections, zoonotic diseases and a possible cross-infection between dorcas gazelles and the G. arabica population. Despite the positive relationship between $G$. dorcas and G. arabica population size, it is recommended to remove all dorcas gazelles from the enclosure. This will ensure that the carrying capacity inside the enclosure is unlikely to be reached and that food and water only benefit the Arabian gazelles. These recommendations and research priorities are in line with the INPA strategic plan for the conservation of G. arabica within the next 5 years (Polack, T., pers. com).

Acknowledgements We thank Tal Polak, Oded Sahar, Eran Hyams, Zohar Ben Shitrit, David Blank, and workers and volunteers of the Israel Nature and Parks Authority, Southern District, for their continuous and dedicated work to monitor and save the Arabian gazelle.

Open Access This article is distributed under the terms of the Creative Commons Attribution 4.0 International License (http://creativecommons.org/licenses/by/4.0/), which permits unrestricted use, distribution, and reproduction in any medium, provided you give appropriate credit to the original author(s) and the source, provide a link to the Creative Commons license, and indicate if changes were made. 


\section{References}

Adamcik RS, Todd AW, Keith LB (1978) Demographic and dietary responses of great horned owls during a snowshoe hare cycle. Can Field Nat 92:156-166

Andelt FW, Althoff DP, Case RM, Gipson PS (1980) Surplus-killing by coyotes. J Mamm 61:377-378

Arsenault R, Owen-Smith N (2002) Facilitation versus competition in grazing herbivore assemblages. Oikos 97:313-318

Baharav D (1980) Habitat utilization of the dorcas gazelle in a desert saline area. J Arid Environ 30:161-167

Bärmann EV, Wronski T, Lerp H, Azanza B, Börner S, Erpenbeck D, Rössner GE, Wörheide G (2013a) A morphometric and genetic framework for the genus Gazella de Blainville, 1816 (Ruminantia: Bovidae) with special focus on Arabian and Levantine Mountain gazelles. Zool J Linn Soc 169:673-696

Bärmann EV, Börner S, Erpenbeck D, Rössner GE, Hebel C, Wörheide G (2013b) The curious case of Gazella arabica. Mamm Biol 78:220-225

Barocas A, Hefner R, Ucko M, Merkle JA, Geffen E (2018) Behavioral adaptations of a large carnivore to human activity in an extremely arid landscape. Anim Conserv 21:433-443

Blank DA (1996) The Acacia gazelle: extinction of a subspecies. Gnusletter 15:7-9

Blank DA (2000) Acacia gazelle increases with habitat improvement. Gnusletter 19:11-13

Blank DA (2001) Haibar reserve. Gnusletter 20:16-17

Blank DA (2005) Sunset of the Acacia gazelle. Gnusletter 24:6-7

Borkowski J, Zalewski A, Manor R (2011) Diet composition of golden jackals in Israel. Ann Zool Fenn 48:108-118

Bothma J, Du P (2002) Game Ranch management. Van Schaik, Pretoria

Boug A, Islam MZ, Al Shehry A, Wronski T (2012) Camera trapping confirms persistence of Arabian gazelles, Gazella arabica, in the Asir Mountains, Saudi Arabia. Zool Middle East 57:3-10

Breslau B, Polak T, Shalmon B, Groner E (2019) Evidence of browsing pressure on the critically endangered Acacia gazelle (Gazella acaciae). J Arid Environ. https://doi.org/10.1016/j.jaridenv.2019.10401 9 online first

Cohen O, Barocas A, Geffen E (2013) Conflicting management policies for the Arabian wolf Canis lupus arabs in the Negev Desert: is this justified? Oryx 47:228-236

Cunningham PL, Wronski T (2010) Distribution update of the Arabian wolf (Canis lupus pallipes) from Saudi Arabia. Wildl Mid East News 5(3):4

Cunningham PL, Wronski T, Al Aqeel K (2009) Predators persecuted in the Asir region, western Saudi Arabia. Wildl Mid East News 4(1):6

DelGiudice GD (1998) Surplus killing of white-tailed deer by wolves in Northcentral Minnesota. J Mammal 79:227-235

Dolev A, Perevolotsky A (2004) The Red Book: vertebrates in Israel. Israel Nature and Parks Authority and the Society for the Protection of Nature in Israel, Tel Aviv

Durant SM, Wacher T, Bashir S, Woodroffe R, De Ornellas P, Ransom C, Newby J, Abaigar T, Abdelgadir M, El Alqamy H, Baillie J, Beddiaf M, Belbachir F, Belbachir-Bazi A, Berbash AA, Bemadjim NE, Beudels-Jamar R, Boitani L, Breitenmoser C, Cano M, Chardonnet P, Collen B, Cornforth WA, Cuzin F, Gerngross P, Haddane B, Hadjeloum M, Jacobson A, Jebali A, Lamarque F, Mallon D, Minkowski K, Monfort S, Ndoassal B, Niagate B, Purchase G, Samaila S, Samna AK, Sillero-Zubiri C, Soultan AE, Stanley Price MR, Pettorelli N (2014) Fiddling in biodiversity hotspots while deserts burn? Collapse of the Sahara's megafauna. Divers Distrib 20:114-122

Elton C, Nicholson M (1942) The ten-years cycle in number of the lynx in Canada. J Appl Ecol 11:215-244

En.climate-data.org (2017) Climate Yotvata: Temperature, Climate graph, Climate table for Yotvata-Climate-Data.org. https://en.climate-data.org/location/914/. Accessed 28 Aug 2018

Evenari M, Shannan L, Tadmor N (1971) The Negev—-the challenge of a desert. Harvard University Press, Cambridge

Geffen H, Perevolotsky A, Geffen E, Yom-Tov Y (1999) Use of space and social organization of female mountain gazelles (Gazella gazella gazella) in Ramat HaNadiv, Israel. J Zool 247:113-119

Gingold G, Yom-Tov Y, Kronfeld-Schor N, Geffen E (2009) Effect of guard dogs on the behavior and reproduction of gazelles in cattle enclosures on the Golan Heights. Anim Conserv 12:155-162

Gordon IJ, Gill P (1993) Re-introduction of Scimitar-horned oryx (Oryx dammah) to Bou-Hedma National Park, Tunisia. Int Zool Yearb 32:69-73

Groves CP (1985) An introduction to the gazelles. Chinkara 1:4-16

Groves CP (1986) The taxonomy, distribution and adaptions of recent equids. In: Meadow RH, Uerpmann H (eds) Equids in the ancient world. Ludwig Reichert, Wiesbaden, pp 11-51 
Groves CP (1997) Taxonomy of Arabian gazelles. In: Habibi K, Abu-Zinada AH, Nader IA (eds) The gazelles of Arabia. National Commission for Wildlife Conservation and Development, Riyadh, pp 24-51

Groves CP, Grubb P (2011) Ungulate taxonomy. John Hopkins University Press, Baltimore

Habibi K (1991) Arabian gazelles. National Commission for Wildlife Conservation and Development, Riyadh

Hadas L, Hermon D, Boldo A, Arieli G, Gafny R, King R, Kahila Bar-Gal G (2015) Wild gazelles of the Southern Levant: genetic profiling defines new conservation periorities. PLoS ONE 10:e0116401

Henderson DS (1974) Were they the last Arabian oryx? Oryx 12:347-350

IMS, Israel Meteorological Service (2018) Climate information. http://www.ims.gov.il/IMSEng/CLIMA TE. Accessed 22 Sept 2018

Islam ZM, Wacher T, Boug A, Wronski T (2011) Population development of re-introduced Mountain Gazelle in the western Empty Quarter (Uruq Bani Ma'arid Protected Area), Saudi Arabia. In: Soorae PS (ed) Global re-introduction perspectives: 2011. IUCN/SSC Re-introduction Specialist Group (RSG), Abu Dhabi, pp 180-184

IUCN/SSC Antelope Specialist Group (2009) Quarter of antelope species in danger of extinction. Gnusletter 28:2-5

IUCN/SSC Antelope Specialist Group (2016) Oryx dammah. The IUCN Red List of Threatened Species 2016: e.T15568A50191470. http://dx.doi.org/10.2305/IUCN.UK.2016-2.RLTS.T15568A50191470 .en

IUCN/SSC Antelope Specialist Group (2017) Gazella arabica. The IUCN Red List of Threatened Species 2017: e.T117582065A88018124. http://dx.doi.org/10.2305/IUCN.UK.2017-2.RLTS.T1175 82065A88018124.en

Keith LB (1963) Wildlife's ten-year cycle. University of Wisconsin Press, Madison

Krebs CJ, Boutin S, Boonstra R, Sinclair ARE, Smith JNM, Dale MRT, Martin K, Turkington R (1995) Impact of food and predation on the snowshoe hare cycle. Science 269:1112-1115

Kruuk H (1972) Surplus killing by carnivores. J Zool 166:233-244

Lerp H, Wronski T, Plath M, Schröter A, Pfenninger M (2013) Phylogenetic and population genetic analyses suggest a potential species boundary between Mountain (Gazella gazella) and Arabian gazelles (G. arabica) in the Levant. Mamm Biol 78:383-386

Magin CD, Greth A (1994) Distribution, status and proposals for the conservation of mountain gazelles Gazella gazella cora in the southwest of Saudi Arabia. Biol Conserv 70:69-75

Mallon DP, Kingswood SC (2001) Antelopes. Part 4: North Africa, the Middle East, and Asia-Global Survey and Regional Action Plans. IUCN/SSC Antelope Specialist Group, Gland

Manor R, Saltz D (2004) The impact of free-roaming dogs on gazelle kid/female ratio in a fragmented area. Biol Conserv 119:231-236

Margolis M, Hyams E, Belcher M (2008) The Diet of wolves (Canis lupus) in En Geddi area, according to analysis of their feces. Zoological Society of Israel, Poster [in Hebrew]

Mendelssohn H (1974) The development of the population of gazelles in Israel and their behavioural adaptions. In: Geist V, Walther F (eds) The behaviour of ungulates and its relevance to management. IUCN Publications, New Series 2, Gland, pp 723-743

Mendelssohn H, Yom-Tov Y, Groves CP (1995) Gazella gazella. Mamm Species 490:1-7

Mendelssohn H, Groves CP, Shalmon B (1997) A new subspecies of Gazella gazella from the southern Negev. Isr J Zool 43:209-215

Miller FL, Gunn A, Broughton E (1985) Surplus killing as exemplified by wolf predation on newborn caribou. Can J Zool 63:295-300

Newby J (2016) They are back! Reintroduction of the scimitar-horned oryx to the Ouadi Rime-Ouadi Achim Game Reserve, Chad. Sandscript 19:1-6

Newby J, Wacher T, Durant SM, Pettorelli N, Gilbert T (2016) Desert antelopes on the brink: How resilient is the Sahelo-Saharan ecosystem? In: Bro-Jørgensen J, Mallon D (eds) Antelope conservation-from diagnosis to action. Wiley-Blackwell and Zoological Society of London, Oxford, pp 253-279

Pekár S, Brabec M (2016) Marginal models via GLS: a convenient yet neglected tool for the analysis of correlated data in the behavioural sciences. Ethology 122:621-631

Pinheiro J, Bates D, DebRoy S, Sarkar D, Team RC (2012) nlme: Linear and nonlinear mixed effects models. R package version 3.0

Putman RJ (1996) Competition and resource partitioning in temperate ungulate assemblies. Chapman \& Hall, London

Reichmann A, Saltz D (2005) The Golan wolves: the dynamics, behavioural ecology and management of an endangered pest. Isr J Zool 51:87-133

Shalmon B (1986) Wolves in the Southern Arava, Israel. Reem 5:60-74 [in Hebrew] 
Shalmon B (1989) The ecology of Gazella gazella spp. in the southern Arava Valley. Isr J Zool 35:97

Shalmon B (1991) Conservation program for the gazelle Gazella gazella acaciae. Gnusletter 10:10-11

Shalmon B (1997) The Aravah gazelle. Israel Land Nat 13:15-18

Shamoon H, Saltz D, Dayan T (2017) Fine-scale temporal and spatial population fluctuations of medium sized carnivores in a Mediterranean agricultural matrix. Landscape Ecol 32:1243-1256

Sinclair ARE (1985) Does interspecific competition or predation shape the African ungulate community. J Anim Ecol 54:899-918

Sinclair ARE, Norton-Griffiths M (1982) Does competition or facilitation regulate migrant ungulate populations in the Serengeti? A test of hypotheses. Oecologia 53:364-369

Soares JF, Desta FS, Macasero W, Butynski TM, Wronski T (2019) Eradication of Brucella melitensis from two captive gazelle populations in Saudi Arabia. J Zool Wildl Med 50:706-712

Stabach JA, Rabeil T, Turmine V, Wacher T, Mueller T, Leimgruber P (2017) On the brink of extinctionhabitat selection of addax and dorcas gazelle across the Tin Toumma desert, Niger. Divers Distrib 23:581-591

Stanley Price MR (1989) Animal re-introductions: the Arabian oryx. Cambridge University Press, Cambridge

Strauss WM, Al Kharousi Y, Spalton A (2009) Status of the gazelle population in the Arabian Oryx Sanctuary of Oman. Wildl Middle East News 3:5

Talbot LM (1960) A look at threatened species. Oryx 5:240-247

Talmon I (2015) Movement ecology of an overabundant Golden jackal (Canis aureus) population in an environment rich with anthropogenic food resources. MSc thesis, Ben-Gurion University of the Negev

Thouless CR, Habibi K, Magin C, Wacher T (1997) Status and distribution of gazelles in Saudi Arabia. In: Habibi K, Abu-Zinada A, Nader I (eds) The gazelles of Arabia. National Commission for Wildlife Conservation and Development, Riyadh

Vesey-Fitzgerald DF (1952) Wildlife in Arabia. Oryx 1:232-235

Wegge P, Shrestha AK, Moe SR (2006) Dry season diets of sympatric ungulates in lowland Nepal: competition and facilitation in alluvial tall grasslands. Ecol Res 21:698-706

Williams JB, Shobrak M, Wilms TM, Arif IA, Khan HA (2012) Climate change and animals in Saudi Arabia. Saudi J Biol Sci 19:121-130

Wronski T (2013) Population development of Arabian gazelles (Gazella arabica) on the Farasan Islands, Saudi Arabia. Zool Middle East 59:189-195

Wronski T, Butynski TM (2014) 'Five minutes to midnight' for Arabian gazelles Gazella arabica in Harrat Uwayrid, north-western Saudi Arabia. Gnusletter 32:3-5

Wronski T, Schulz-Kornas E (2015) The feeding ecology of Arabian gazelles (Gazella arabica) on the Farasan Islands, Saudi Arabia. Mamm Biol 80:87-95

Wronski T, Wacher T, Hammond RL, Winney B, Hundertmark KJ, Blacket MJ, Mohammed OB, Flores B, Omer SA, Macasero W, Plath M (2010) Two reciprocally monophyletic mtDNA lineages elucidate the taxonomic status of Mountain gazelles (Gazella gazella). Syst Biodivers 8:119-129

Wronski T, Islam ZM, Plath M (2013) Latrine survey as a method to estimate the population size of Arabian gazelles (Gazella arabica). Mamm Biol 78:226-230

Wronski T, Sun P, Plath M (2017a) Resource availability predicts the distribution of Arabian gazelles (Gazella arabica) on Farasan Islands. In: Ward C (ed) Wildlife: perceptions, threats and conservation. Nova Science Publishers, Hauppauge, pp 1-16

Wronski T, Hoffmann M, Plath M (2017b) Habitat preferences of Arabian gazelles (Gazella arabica) in the Farasan Islands Protected Area, Saudi Arabia. In: Menendez A, Sands N (eds) Ungulates: evolution, diversity and ecology. Nova Science Publishers, Hauppauge, pp 65-89

Yom-Tov Y (2013) Human impact on wildlife in Israel since the nineteenth century. In: Orenstein D, Tal A, Miller C (eds) Between ruin and restoration: an environmental history of Israel. The University of Pittsburgh Press, Pittsburgh, pp 53-81

Yom-Tov Y, Ilani G (1987) The numerical status of Gazella dorcas and Gazella gazella in the southern Negev desert, Israel. Biol Conserv 40:245-253

Publisher's Note Springer Nature remains neutral with regard to jurisdictional claims in published maps and institutional affiliations. 


\section{Affiliations}

\section{Benny Shalmon ${ }^{1,2} \cdot$ Ping Sun $^{3} \cdot$ Torsten Wronski $^{4}$}

1643 Marva Lane, Eilat, Israel

2 Israel Nature and Parks Authority (INPA), Southern District, Eilat, Israel

3 Faculty of Forest and Environment, University for Sustainable Development Eberswalde, Schicklerstraße 5, 16225 Eberswalde, Germany

4 Faculty of Science, School of Biological and Environmental Sciences, Liverpool John Moores University, Byrom Street, Liverpool L3 3AF, UK 